\title{
Transdisciplinary Collaboration in ESD Teacher Education Programs
}

\section{Dr. Christian Hoiß'}

\begin{abstract}
Putting Education for Sustainable Development(ESD) into effect will become a major task for the 21 st century, particularly for future teachers who are expected to participate in ESD but whose studies often do not prepare them for this task. This article responds to the question how collaboration in teacher education can help bridge that gap and how it can contribute to the transdisciplinary demands of ESD. It assumes an essential role in enabling collaborative spaces of dialogue and transfer of knowledge between educators and students of all academic disciplines, schools, universities, local stakeholders, and CSO. This specifically includes perspectives from the Global South.
\end{abstract}

Presenting the certificate program "el mundo - ESD in university level teacher education" (LMU Munich) as an example for collaborative ESD practice, the article identifies and presents four central fields of transdisciplinary collaboration in teacher education: contentrelated, institutional, and biography-affecting collaboration, as well as collaboration in pedagogical-didactic contexts.

Key words: Education for Sustainable Development, teacher education, planetary boundaries, collaboration, interdisciplinarity, transdisciplinarity.

Fecha de recepción: 15 de marzo de 2020.

Fecha de admisión definitiva: I5 de junio de 2020.

${ }^{1}$ Ludwig-Maximilians-University Munich, Germany. 


\section{Collaboration transdisciplinaire dans les programmes de formation des enseignants en EDD}

Résumé: La mise en œuvre de l'éducation au développement durable (EDD) deviendra une tâche majeure pour le 21 e siècle, en particulier pour les futurs enseignants qui sont censés participer à l'EDD mais dont les études ne les préparent souvent pas à cette tâche. Cet article répond à la question de savoir comment la collaboration dans la formation des enseignants peutaider à combler ce fossé et commentelle peut contribuer aux exigences transdisciplinaires de l'EDD. II assume un rôle essentiel en permettant des espaces de collaboration de dialogue et de transfert de connaissances entre les éducateurs et les étudiants de toutes les disciplines universitaires, les écoles, les universités, les acteurs locaux et les OSC. Cela inclut spécifiquement les perspectives du Sud global.

En présentant le programme de certification « le monde - EDD dans la formation des enseignants au niveau universitaire » (LMU Munich) comme exemple de pratique de collaboration EDD, l'article identifie et présente quatre principaux domaines de collaboration transdisciplinaire dans la formation des enseignants: en matière de contenu, au contexte de relations institutionnelles, dans le cadre de relations professionnelles qui affectent positivement les biographies académiques, ainsi que des collaborations dans des contextes pédagogique-didactiques.

Mots clé: Éducation au développement durable, formation des enseignants, frontières mondiales, collaboration, interdisciplinarité, transdisciplinarité

\section{Colaboración Transdisciplinaria en Progra- mas de Formación Docente EDS}

Resumen: La puesta en práctica de la Educación para el Desarrollo Sostenible (EDS) se convertirá en una de las principales tareas del siglo XXI, especialmente para los futuros docentes que se espera que participen en la EDS pero que, por lo general, no han sido preparados para ello durante sus estudios.

Este artículo responde a la pregunta sobre cómo la colaboración en la formación docente puede ayudar a salvar esa brecha y cómo puede contribuir a las demandas transdisciplinarias de la EDS. Asume un papel esencial en la habilitación de espacios de colaboración para el diálogo y la transferencia de conocimientos entre educadores y estudiantes de todas las disciplinas académicas, colegios, universidades, grupos de interés locales y organizaciones de la sociedad civil (OSC). Esto incluye específicamente perspectivas del Sur Global.

Mediante la presentación del programa de certificación "el mundo - EDS en la formación de profesorado de nivel universitario" (LMU Munich) como ejemplo de práctica de colaboración EDS, el artículo identifica y presenta cuatro ámbitos principales de colaboración transdisciplinaria en la formación docente: colaboraciones en materia de contenido, en el contexto de relaciones institucionales, de relaciones profesionales que afectan positivamente sus perfiles académicos y de colaboraciones en contextos pedagógico-didácticos.

Palabras clave: Educación para el Desarrollo Sostenible, formación docente, fronteras planetarias, colaboración, interdisciplinariedad, transdisciplinariedad 


\section{Introduction: the planetary boundaries}

Even though global transformations have always been the default mode for life on Earth, the past decades have shown a new quality of change ${ }^{2}$. For 12,000 years mankind has been able to take advantage of an ecological niche in order to spread all over the world and steadily increase its global impact. This, geologically speaking, very short phase of the so-called Holocene is the only state of the Earth which is known to sustain our species (cf. Gerten \& Schellnhuber 2016, 11). Any changes of its global systems (atmosphere, hydrosphere, biosphere, geosphere) automatically pose an existential risk for mankind since no one can predict whether we will be able to adapt accordingly.

And yet, a massive destabilization of life-sustaining global systems has been initiated in the 1950s, a process which is often referred to as the Great Acceleration. It is characterized by an exponential consumption of resources mainly in the Global North: An exponential rise for example in water, paper and fertilizer consumption, as well as in tourism, telecommunication or transportation worldwide has caused dire problems in global earth systems like tropical forest loss, decreasing biodiversity, climate change or ocean acidification to name only a few. The exponentially growing graphs are popularly referred to as hockey stick curves (cf. Steffen, Broadgate, Deutsch et al. 2015). Population growth and changes in lifestyles have amongst others accelerated these socio-economic and earth systemic effects.

A sustainable development for all mankind, future generations in particular, can consequently only be reached if the consumption of resources are reduced and limited to keep a "safe operating space for mankind" (Rockström, Steffen, Noone et al. 2009, 472). This operating space limits human activity by accepting the so-called planetary boundaries, some of which have unfortunately already been crossed. Staying within these boundaries will become the major collaborative challenge for mankind in the 21 st century - with our backs against the ropes since the window of opportunity to radically change the human impact on global ecosystems continues to close (cf. UNEP 2013, Xi).

\footnotetext{
2 This article is based on the work within the certificate program "el mundo - ESD in teacher education" at the Ludwig-Maximilians-University Munich which is generously funded by the Federal Ministry of Education and Research. El mundo is part of the "Qualitätsoffensive Lehrerbildung", a joint initiative of the Federal Government and the Länder which aims to improve the quality of teacher education. The author is responsible for the content of this publication.
} 


\section{Education for Sustainable Development and Teacher Education}

This is the overall background of the concept of Education for Sustainable Development (ESD) which has been increasingly promoted by the United Nations since the Rio Earth Summit in 1992. The framework of ESD is neither one single theory nor does it converge all existing educational frameworks focusing on global ecological, social, economic and cultural issues. In general, ESD combines two paradigms into a new one: environmental protection and the eradication of poverty. The ecological consequences of human activity on a global and local scale are systematically linked to questions of global justice, poverty, human rights, the distribution of privileges, and the exclusion of the Global South in social, cultural, political and economic areas of life. ESD has been an approach to focus on these interdependent aspects within a pedagogical framework attempting to create a bridge between the theoretically complex, interdisciplinary relations and hands-on practice which aims at empowering people to act according to the goals of a sustainable development (cf. Michelsen \& Fischer 2016, 330).

Today, ESD is the key concept intertwining ecological, social, economic, political, and cultural issues on a global scale for learners of all ages and is strategically implemented by the United Nations to develop a world-wide impact in all areas of life. Decision-makers for such a transformation of society are not only to be found in politics, the industry or globally involved institutions. They also exist in educational settings for all ages and qualifications, pre-primary, primary, lower secondary and upper secondary education, higher education institutions (HEI) and all extra-institutional organizations which foster ESD thinking and activities in formal and informal learning spaces.

Teacher education must take a stance on these global issues as well. Given the presented context, the leading question in teacher education must not be whether we should give our full attention to the challenges rising with overstepping the planetary boundaries but rather how. Accordingly, this article focuses on ESD in teacher education in particular which always has an (indirect) influence on all other educational settings.

As its main objective, it responds to the question how collaboration on various levels can be initiated in teacher education and how it can contribute to the transdisciplinary demands of ESD in light of the current global transformations outlined in the introduction. At the same time, the article addresses the theoretical challenge for ESD to develop a pedagogically sound foundation which is guided 
by its own educational principles using Wolfgang Klafki's Education Theory, in contrast to merely following a global political assignment.

Based on the certificate program "el mundo - ESD in university level teacher education" (LMU Munich) this article discusses an example for collaborative ESD practice. The article identifies boundaries in ESD teacher education and presents central fields of collaboration which are key to overcome these boundaries with a transdisciplinary and holistic approach.

\section{ESD between pedagogy and politics}

There is, however, one epistemological constraint which is only brought to one's attention very rarely: ESD is a rather normative pedagogical-didactic approach with a clear set of values at its core, e.g. a strong appreciation of sustainable lifestyles, human rights, gender equality, promotion of a culture of peace and non-violence, global citizenship and cultural diversity and various culture's contributions to sustainable development (cf. UNESCO 2019, 7). But since we are dealing with a politically endorsed educational program - the United Nations are as a matter of fact part of a political system - education as an academic discipline should be reflecting the assumptions of ESD closely. Education must not be reduced to being a bare extension to political organizations. Education does not want to be functionalized, its actors and institutions should not be seen as a lever for institutional change within the ESD framework. Instead, education approaches these issues and participates in the debates because the engagement between a human being with the world and on this world is at its core, because it is the integral element of education's selfconception (cf. Hoiß 2019, 61-69). This assumption and the implied pedagogical approach are guiding principles for the work presented.

In general, when it comes to identifying relevant content in an ESD context, the academic and practical discourse refer to the Sustainable Development Goals (SDGs) - even though these goals have not primarily been scripted for the educational sector but for all areas of life. The 17 SDGs are "at the heart" of the UN's 2030 Agenda for Sustainable Development and "recognize that ending poverty and other deprivations must go hand-in-hand with strategies that improve health and education, reduce inequality, and spur economic growth - all while tackling climate change and working to preserve our oceans and forests" (UN 2015). 169 subgoals break down the major global challenges for the $21^{\text {st }}$ century which can be helpful in finding orientation in this wide range of topics and show the complexities 
of the world. Among others, these goals focus on topics such as biodiversity and ecosystems, chemicals and waste, desertification, disaster risk reduction, finance, forests, gender equality and women's empowerment, oceans and seas, sustainable tourism, transport, violence against children or water and sanitation ${ }^{3}$. Education Theory ("Bildungstheorie") can however build a pedagogical-didactic foundation which is not at the mercy of global political interests but aims for a holistic approach. It has the means to address the "characteristic key issues of any era" ("epochaltypische Schlüsselprobleme"; cf. Klafki 2007, 10) while being guided by its own educational principles. The educationist Wolfgang Klafki for example answered the problem of what the "material side", i.e. the contents within the idea of a general education could be, by defining key issues that matter to every human being at any given time. In such an educational framework people acquire the skills and capabilities to grasp collectively shared key issues within their historically constituted present while facing an emerging future (cf. Klafki 1990,94). They learn how to deal with these "collective tasks, problems and dangers" (Klafki 1990, 94; transl. C.H.) with a spirit of solidarity which is at the base of an individual and a collective feeling of responsibility - not because it is urgent, but because it is a holistic way to enter the world. Teacher education programs, which strive for a holistic educational approach, will be challenged to walk the extra mile and build such a multi-facetted pedagogical foundation despite many structural obstacles (cf. section 5).

Klafki presents the following key issues (cf. 1990, 95-98) and points out that all of them are subject to an on-going process of change. Therefore, they must be updated regularly:

- creating and maintaining global peace in times of nuclear, biological and chemical weapons (today certainly supplemented by the risks of digital warfare),

- environmental protection, reduction of environmentally harmful activities, and developing a stronger awareness concerning the risks of an uncontrolled and irresponsible industrial and technological development and its consequences,

- a permanent democratic control of economic-technological science-driven innovation, including strong and on-going political communication and transparency, as well as the institutionalization of democratic supervisory authorities,

- overcoming socially produced inequality within our own society (e.g. gender inequality, discrimination against people with disabilities) as well as globally

${ }^{3}$ For a comprehensive, systemic and very concise collection of sustainability topics see Scott \& Vare 2017. 
(e.g. differences in power, privileges and prosperity between so-called developed and less developed countries),

- chances and risks of modern information technology,

- the relevance of so-called "I-You-relationships" (Klafki 1990, 97) which contains the area of individual pursuit of happiness, interpersonal responsibility and acknowledging the existence and needs of another person (e.g. in experiences of love, in regard to human sexuality and sexual orientation).

It almost goes without saying that these issues do not stop at national or continental borders; that is why they have to be integrated in a global perspective which always takes the historical context into account (cf. Klafki 1990, 94). They are not only knowledge-based but they also stress the necessity to reflect on one's own attitudes and values (cf. Klafki 1990, 98).

\section{The certificate program "el mundo - ESD in teacher education"}

The certificate program "el mundo - ESD in teacher education" launched at the Ludwig-Maximilians-University Munich in the winter term 2019/20 (see www. Imu.de/elmundo). It is an additional course of studies offered to all students within LMU teacher education who will teach any subject in any type of school. El mundo prepares for the challenges of a globalized world and raises awareness for aspects of sustainability in teaching and operating schools. The program takes place parallel to students' regular course of studies and includes five modules with 30 ECTS in total.

El mundo follows three pedagogical principles which are key in addressing global issues like climate change, global injustice, or biodiversity loss:

- open and nonviolent discourse (with a focus on discourse processes and theory as a basis for value-oriented acting and teaching),

- embracing a multitude of perspectives in an inter- and transdisciplinary context,

- as well as a strong emphasis on self-reflection (individual, collective, pedagogical, didactic).

The project assumes an essential role in enabling spaces of dialogue and transfer of knowledge between educators and students of all academic disciplines as well 
as schools, universities, the local administration, and Civil Society Organizations (CSO). Within these spaces, the perspectives of the Global South are especially addressed.

El mundo establishes an innovative approach for environmental and societal communication in pedagogical-didactic contexts and develops a socio-ecologically oriented vision of teacher education in the 21 st century. On a local and regional scale, it can serve as an inspiration for educators in various fields and learning settings, encourages students through participatory elements to get involved in ESD challenges and helps develop an authentic role in the teaching process of ESD.

In particular, el mundo promotes

- stronger perception and sensibility for the relationship between nature, humans, and their environment through processes of self-reflection

- willingness to shape the direct surroundings (with the university and school environment as a starting point) based on the concept of ESD

- a willingness to actively confront socio-ecological challenges in a globalized world by complex and systematic thinking

- openness for cultural diversity and the development of a global citizenship

- awareness for the special meaning of discourse mechanisms and critical thinking when negotiating value-driven decisions (cf. Stoltenberg \& Holz 2017).

One essential premise shall be stated at this point: El mundo does not suggest that a change in socio-ecological or environmental behavior is supposed to be at the core of a teacher education program. Democratic power-critical considerations do not allow strategic targeting of future educators for any purpose including ESD. It is therefore not trying to convince anybody to change their teaching philosophy and/or teaching environment; it describes guidelines for future teachers who want to establish a culture of sustainability in their educational environment based on an on-going and transparent process of self-reflective judgements. 


\section{Transdisciplinary Collaboration in ESD Teacher Education Programs}

This article particularly responds to the question how collaboration on various levels can be initiated in teacher education settings in $\mathrm{HEl}$ and how it can contribute to the transdisciplinary demands of ESD. The following image outlines four different categories of collaboration that are central in describing transdisciplinarity in ESD teacher education.

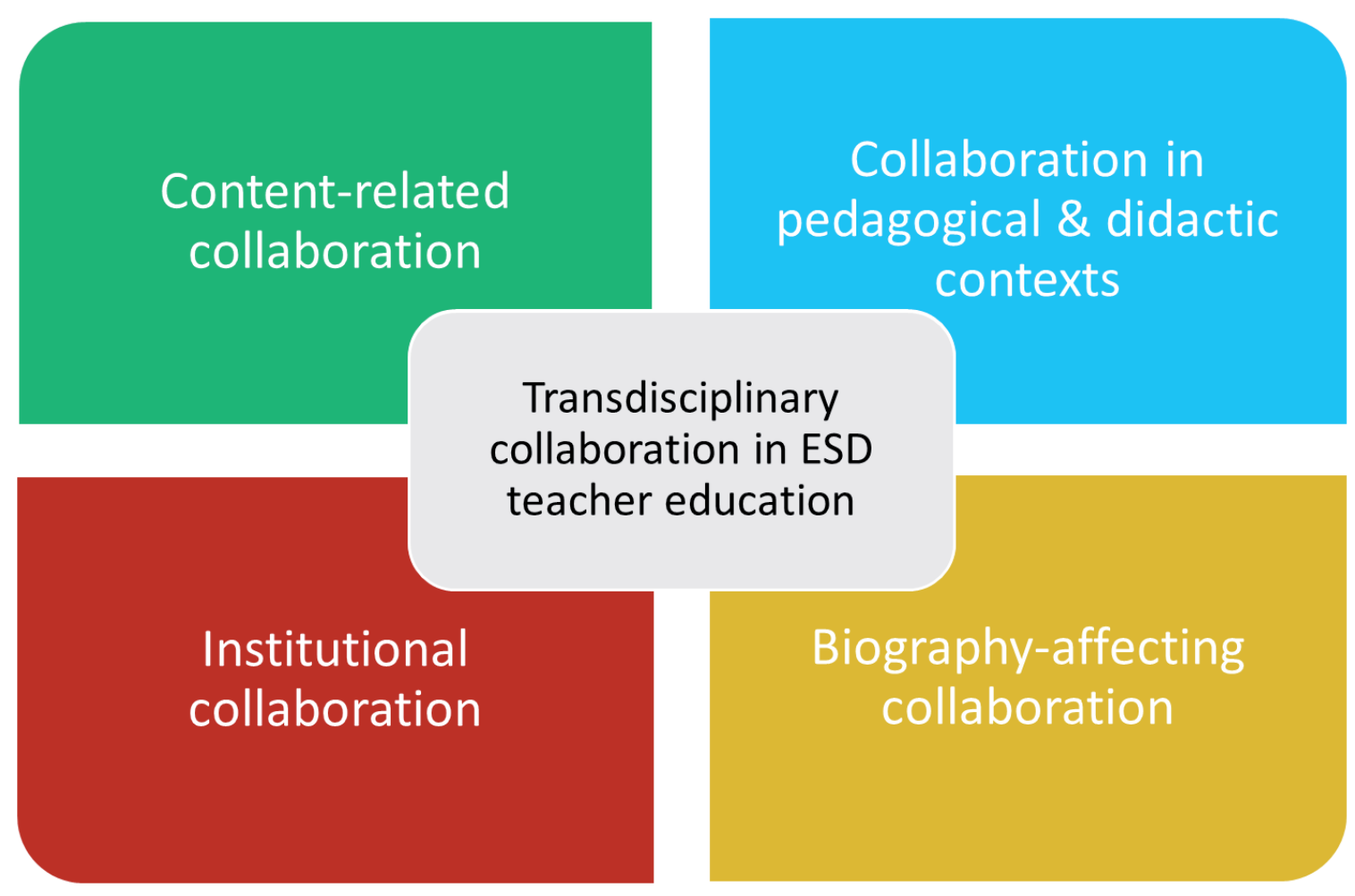

Figure 1: categories of transdisciplinary collaboration in ESD teacher education.

These fields of collaboration have proven vital in the establishment of the above mentioned el mundo program and will be explained in the following sections. The categories suggested are certainly interwoven in many ways, as will be shown below. However, their clear-cut separation has epistemological reasons and serves to disentangle some aspects of ESD teacher education which could easily be taken for granted or not considered. 
Content-related

collaboration
- Necessity of inter- and transdisciplinary approaches in ESD

- Multi-perspective approach

- Combination of ESD with subject-related didactics

Figure 2: elements of content-related collaboration in ESD teacher education.

Creating an ESD environment that meets the requirements of all spheres of sustainability (ecological, social, economic and cultural) necessarily demands complex and interdependent interaction between various disciplines because sustainability problems in general contain aspects of all fields. Holistic pedagogical approaches like the UNECE framework Learning for the Future (2011) or the framework developed by the project A Rounder Sense of Purpose (RSP; cf. Farioli, Mayer \& del Gobbo 2017) consequently try to combine and interrelate the various theoretical concepts, methods and specific means of problem-solving. This is important to generate a society-driven process to a sustainable development in which any actor (student and teacher) can solve existent problems with a systemic perspective that takes multiple fields of science into consideration (cf. Kruse 2005, 110).

It becomes evident that all these topics are dynamically interwoven and directly linked to other topics (for example chemicals/waste and health). This is also the reason why none of these challenges can be solved by only one or few disciplines or actors. From a pedagogical perspective, it is a must to reach beyond single exemplifying topics. According to Klafki's theory (cf. section 3), every topic must have its concrete, exemplifying core, which, however, must always be integrated into a more general context. The same applies to ESD which can be a broad and bright mosaic of topics with single shards of all different shapes and colors. Yet, at the end of the day, ESD students (and teachers!) should be able to see the mosaic as a whole - a task that can only be reached by transdisciplinary collaboration which clearly involves Education Theory as a unifying frame.

Hence, it becomes inevitable to stronger connect all relevant disciplines in ESD teacher education. Climate change, for example, is only at first glance a geographical or meteorological problem. Of course, these disciplines describe the on-going phenomena (and have first brought it to our attention), draw conclusions from a multitude of measurements and model climate scenarios for the foreseeable future. Leaving aside that they need statistics or machine learning to do so, facing climate change also involves any other discipline there is: the medical sector deals with increasing health risks caused by climate change; economists analyze possible shifts in the market; humanities describe climate change as a cultural phenomenon in 
language, media, literature, art and music; ethics or law discuss implications and effects of climate change on various systems...

Connecting the various topics of ESD with the conventional content of traditional school subjects is, however, not at all trivial - mainly, because subject didactic related research (e.g. in language learning) is still dormant when it comes to the collaborative challenges of sustainable development. At the same time, at least in the German school system, teachers are still prepared to study between 2 and 4 independent school subjects like maths, history, or languages which each focus exclusively on their very field of interest. Traditionally, however, only few disciplines deal with issues related to the field of sustainable development.

This leads to a number of misconceptions: (i) the young student teachers define their role mostly as a teacher of few specific subjects, leaving out any topics and relations that exist beyond the boundaries of their majors and likely define the character of ESD; (ii) in educational institutions it is still widely acknowledged that the subjects which deal with human-nature-relationships (i.e. geography and biology) are the ones in charge of "topics like climate change", giving an excuse to all other subjects not to get involved; (iii) since ESD issues play at best a marginal role in many subject-related teacher education programs, this could lead to the assumption that the relevance of ESD is not high, otherwise it would be involved in curricula and (state) examinations.

The systematic gap becomes obvious: future teachers are on the one hand expected to participate in ESD. Yet on the other hand there is no specific point in their course of studies which would address the question of how to do ESD and how to relate it to their future students - even though ESD has been added to many curricula in the last decade. Furthermore, because ESD is not visible in any structures of teacher education (faculties, curricula, exams, requirement for academic positions etc.), they contribute to a distorted picture of reality in which ESD is not a relevant issue for future teachers.

Collaboration in

pedagogical \& didactic contexts
- Discourse-oriented and collaborative approach

- Reflective attitude towards power mechanisms in education

- Participatory approach

Figure 3: elements of collaboration in pedagogical and didactic contexts in ESD teacher education. 
For that reason, the teacher education programs should put a strong emphasis on the connection between ESD and subject-related knowledge. Corresponding to the line of argumentation above, ESD cannot be seen only as an "add-on" in a specific subject culture or as a top-down order which has to be exerted due to political pressure. On the contrary, ESD offers a strong potential for innovative transformation for any discipline. It raises questions which can only be solved by a collaborating approach taking the answers of all individual disciplines into consideration. This way the disciplines can contribute new knowledge to existent challenges - a knowledge which is generated from within the core of a discipline (using typical methods and theoretical frameworks). That way the disciplines can develop a genuine contribution to theoretic, empirical and practical research in ESD while at the same time innovating the own field of expertise. This process can ultimately lead to a didactically driven culture of sustainability.

The interdisciplinary field of sustainable development urges education to follow suit and develop suitable theoretical frameworks and methods, if education wants to live up to the idea that scientific knowledge should be at the center of its curricula and guiding its teaching conventions. This chapter will highlight some of the consequences and implication concerning collaborative strategies in educational settings when trying to meet the requirements of interdisciplinarity.

It is rather apparent that the numerous topics in ESD are fuzzy, controversial, and not at all clear-cut. ESD topics are highly normative, also heavily debated in public and usually do not easily find consent among various actors. To give just one example: Even though global climate change is widely recognized as threat to humanity, strategies to tackle the problem vary extremely (e.g. between mitigation and adaptation strategies). While some demand a decreasing consumption of fossil fuels, an instant ban of combustion engines in the car industry or the end of oil-fired heating systems, others fear the loss of jobs in certain industries and oppose such ideas. It quickly shows that a transformation of our society might be desirable in the face of an on-going threat to the planetary boundaries, however, such change does not seem to be desirable to every member of our societies. Further, among the group that promotes change the paths and goals of such a transformation remain somewhat undefined; like so many ethical and political issues, they continue to be subject to negotiations and debates.

Negotiating such issues with an interdisciplinary approach can foster students' abilities to (at least partially) take on someone else's perspective (of a person from a different part of the world, other generations or possibly other species and also of a different academic discipline) and to develop the willingness to do so. By 
practicing various forms of discourse, students also learn to observe, analyze and negotiate different normative concepts behind various kinds of positions. They learn to critically reflect on their own attitudes, values and positions inside and outside their teacher roles and give thought to the normative impact which ESD has on their disciplines as well as their personal and professional lives.

ESD is not likely to be a "feel-good" approach in the classroom. It creates spaces for open discussion, negotiation and solutions but mostly cannot offer straight-forward answers to the challenges of society. Discussions will most likely not lead to clear results, negotiations might not lead to satisfying compromises and there might not be broad agreement within the classroom. The openness of the educational discourse certainly asks a lot from educationists, most of all that they cannot know the result of their classes beforehand. Discourse itself will be the pedagogical goal, rather than a pre-determined result. If they take basic principles of discourse theory seriously, they will collaborate with their students more than teach them the "right" answers (which would be impossible to know!). In addition, since many of the ESD topics also have a strong tendency to align with certain political views, it must be a prerequisite for ESD teaching to reflect on those political implications (cf. Hoiß 2019 , 246-249). As educationists, we have to learn never to impose our own beliefs and values linked to our ideas of a sustainable development on our students. We have to reflect upon the power dynamics in institutional classroom environments and must not use the classroom as a platform for our own political views. Since transparency is key in ESD, these issues should be addressed with our students.

Authentic collaboration with our students requires all participants to accept differences in world views, strategies and solutions. The social bond between all actors must not be torn despite any disagreements that might occur. When we create such a democratic, transparent and discourse-oriented environment, the classroom can become a collaborative arena in which (scientific) arguments, values and views on the world are openly facing each other. Key principles in such an educational discourse are based on transparency, democracy, appreciation of diversity and diverse points of view, willingness to communicate and engagement in public discourse, readiness for empathy and taking in diverse perspectives on the world.

ESD-oriented teacher education will focus on these issues and raises awareness for the following collaborative challenges:

- addressing characteristic key issues of our time (cf. Klafki) by integrating subjectrelated knowledge in ESD thus creating "real" collaboration and subject-driven innovative methods 
- challenging participants' teaching philosophy and their ideas of their teacher roles particularly regarding a collaborative way of working with their students

- linking ESD-related issues directly to the everyday life of all participants (for example at school) by referring to their individual experiences, means of communication and opportunities to act,

- encouraging students to strong participation along the whole process of their education,

- thus, regularly creating moments of self-efficacy which positively influence students' idea of their teaching personality,

- using student teachers' practical experience in ESD for analytical observations, collaborative feedback, and processes of self-reflection (e.g. by video-graphed lessons organized by the teacher education program or within an internship),

- reflecting the normative and ethical implications of ESD and learning to implement them in the classroom in an appropriate way.

Concerning the collaborative inter- and transdisciplinary challenge it is vital for (future) educators to be able to "identify and express their own values and perspectives and the strengths and limitations of these within a given context related to sustainability" (RSP 2018). It is equally important to stress certain fields of expertise and interest, not trying to get involved in too many different aspects at a time. The collaborative approach should take away the pressure of having to know every single detail in any given field. This is a common misconception of what is expected of an educationist in an ESD context. Collaborating in an interdisciplinary teacher education setting means for example to discuss the ecological footprint with students majoring in mathematics or economics even though I, as the teacher, might not have an academic background in these fields and might be completely dependent on their understanding of the statistics behind different footprint concepts. This process certainly requires trust among all participants and does not define the "teacher" as the gatekeeper of knowledge. At the same time, all participants including the teacher can learn from multiple perspectives.

The participatory approach helps learners to actively share ideas (e.g. for teaching materials or lessons) and experience direct feedback. This can be reached inside the classroom, in experimental lessons, project-based work, internships or other ESD related extra-curricular activities. Students "[r]ecognise their potential contribution towards societal transformations for sustainable development" (RSP 2018) and might even be encouraged to "[p]ropose, facilitate and participate in actions that will trigger transformations of systems and unsustainable practices" (RSP 2018). Such 
processes cannot be forced upon people, but they will happen as side-products given a certain interest in students and given a range of opportunities. These opportunities can for example be offered at the start of each seminar with a time slot dedicated to current events, workshops or other activities that invite students to become engaged in the local or regional communities.

\section{Institutional} collaboration
- Content-related academic networks (faculties and universities)

- Exchange with CSO and schools

- Internal networks (multiple stakeholders, whole institution)

Figure 4: elements of institutional collaboration in ESD teacher education.

In order to bring the content and pedagogy related collaborative opportunities to life and to implement them in academic contexts, it is important to systematically collaborate on an institutional level. Four areas appear to be crucial in this context:

Firstly, one needs to establish strong content-related academic cooperation inside and outside one's own university. Inside your own institution, you have to identify stakeholders who also work in ESD or related fields (e.g. environmental ethics, environmental history etc.) to be able to engage in active discourse, invite people to workshops or similar educational events, integrate their lectures in your own teaching program and build a strong local support network that helps dealing with any up-coming obstacles. Joining region- or nationwide as well as international ESD networks is essential to be informed about latest developments in the field and can help to get advice from other stakeholders who might have dealt with a similar problem a long time ago.

Secondly, regular exchange with other researchers and practitioners in ESD especially with actors outside of HEl helps to reflect your own perspective and notice the shortcomings and limitations but also the strengths of your own approach, discipline and institution. Collaborating, for example, with CSO who have specialized in Global Learning will challenge one's own perspective on cultures, economics, power and privilege profoundly and will help to reflect and deconstruct Eurocentric perspectives and ideologies ${ }^{4}$. Regular collaboration with other researchers in ESD will help to deepen your understanding of the field and get valuable insights in their research focus which usually vary widely from theoretic to empirical or practical

${ }^{4}$ The list of cited works shows that there is still a lack of diversity in ESD research. More often than not, the white European voice dominates the discourse. 
work. Collaboration with CSO will unfold a whole new approach to ESD because they are less likely to work with a scientific focus but are more hands-on using well-established methods and deductively draw conclusions from the outcome of the method used. Much more than educationists from institutionalized backgrounds, they often have an activist approach and let people get insights in their philosophy, their motivation and their effective goals. Many students perceive this as a rather refreshing supplement to the usual observing, analyzing and reflecting academic approach. For academic purposes it is very beneficial due to the number of methods which have often served as an incubator for innovative changes in teacher education courses.

Thirdly, connections with participating local schools show multiple advantages. The schools benefit from young teaching students who -that is the case in the el mundo program- get the chance to experiment in a number of ESD related lessons because not only the students get first-hand and up-to-date information on highly relevant topics but also the supervising teachers who quite often do not have the time to stay thoroughly informed in manifold interrelated fields of ESD. Teacher students get practical experience and will have first-hand feed-back on whether their planned lesson reached its goals. In filmed lessons students will additionally receive feedback on various aspects of teaching (e.g. communication style, questioning techniques, discourse behavior) from the school supervisor, the university lecturer as well as their peer students. HEI will also benefit since their impact multiplies when their students teach a new generation of students according to the latest findings and to current academic standards. When observations made within school settings are being documented, discussed and analyzed, the school lesson can again have an influence on the academic work (feedback loop). This transdisciplinary arrangement can strengthen academic research on ESD while at the same time university directly engages with non-academic fields of society and overcomes the much-criticized knowledge gap between academia and society. Thus, teacher education programs can play an important role in promoting spaces of dialogue and knowledge cocreation between HEl and CSO.

Finally, a strong network within one's own institution is key. This network ideally consists of all relevant levels and areas of the institution (whole-institution-approach) which at $\mathrm{HEl}$ usually contains academic staff, administrative staff including campus operations, students, and governance. Depending on the network's specific goal it can be helpful to get all relevant stakeholders involved (multi-stakeholder-approach). In the case of an ESD teacher education program one will need a strong network and many supporters to initiate such a program in the first place. The academic purpose must be presented to governance bodies for a lean structural implementation. 
Funding has to be secured for which you will have to involve ministries or other relevant authorities. Student associations should be engaged at an early stage to foster participation at an early stage and take the needs and perspectives of the future participants into account who should benefit most from the program. In addition, collaboration with various faculties should be initiated whose coordinators and staff should be informed about the contents and be willing to support with advertising or opening relevant lectures for the program's participants. They can also provide various experts in ESD related fields who can be consulted for interdisciplinary issues.

Biography-affecting collaboration
- Affirmation and support through visibility of ESD programs - Horizontal collaboration within one generation of students - Vertical collaboration between generations of teachers

Figure 5: elements of biography-affecting collaboration in ESD teacher education.

Research on teacher personality and identity strongly suggests the importance of authentic and affirmative role-models. Hence, it is crucial to establish visible ESD programs which can offer such role models. If ESD is not visibly implemented in teacher education, students might also be under the assumption that there are more important issues to deal with and will not see ESD-related questions as an integral part of their own teacher identity. ESD teacher education programs will at the same time support those students who already see the necessity of ESD in teacher education but have not been offered the chance to relate it systematically and academically sound into their education. Feedback to the launch of the el mundo program has shown exactly that: students claimed they have been waiting for ESD to become visible in their course of studies and felt somewhat desperate that the institutional sector has not offered them any related courses until then. Students described it as some sort of institutional cognitive dissonance that our Earth seems to be burning, yet teacher education largely decides not to address that problem - even worse: education decides not to discuss with students how to deal with those global challenges as future teachers and consequently risking that another generation of students will not be taught within ESD frameworks. Implementing ESD in teacher education programs can have a strong impact on future teachers' biographies and support them finding an affirmative and appreciating way to integrate ESD related values, attitudes and positions in their self-concept as a teacher.

At the same time, ESD programs in teacher education can be a platform for networking and debate to students who mostly do not have a community. Students have repeatedly stressed the high value of such a program for their own self-concept. 
They reported that they very often feel like the "odd-one out", being marginalized among peers as a teacher student with a strong interest in socio-ecological topics. The feeling intensifies when their education program in addition marginalizes ESD, potentially causing inner tensions regarding their role (as a teacher) in the world. ESD programs in teacher education can have a strong counter-effect. They can address the double marginalization of their students and support their engagement. Furthermore, they can initiate support networks among peer-students that converts their marginalization into active engagement and shared affirmation. It is not unlikely that these networks can have a long-term effect on future teachers' biographies and their work in ESD. The strong ties that develop between the students and the CSO networks as described above add to this effect. The network built in their ESD programs will also be very beneficial in their future educational work when they can reproduce the collaborative approach in their future classes by reaching out to practicing CSO and colleagues from other schools or institutions.

ESD programs in teacher education can also create an intergenerational link. In their studies, students will discover the historical roots of ESD and that the generations before have not only shown a strong interest in ESD related topics le.g. the environmental approaches in the 1970s, 80s and 90s, peace education concepts during the Cold war, or Freire's Pedagogy of the Oppressed to name just a few) but laid the groundwork for today's concepts and thus influencing our own biographies. Today's students will not only form networks with peers from their generation but also with "peers" from former generations, many of which are still actively engaged in formal and non-formal educational settings and certainly are another group for future collaborations. Intergenerational collaborations in ESD contexts seem particularly important because

- all generations can learn from each other (e.g. by reflecting on successes and failure concerning sustainability issues),

- they will join a debate about their specific needs and wishes which can be very helpful given the current debates on blaming older generations for their failure in climate protection or the younger generation's fear of a bleak future,

- they offer another perspective which can help solving interdisciplinary challenges,

- they can be very consolidating showing older generations that their educational work will be continued,

- the existence of an engaging younger generation of teachers is proof for the older teacher generations' educational success. 
It becomes obvious that ESD teaching can strongly benefit from horizontal collaboration (i.e. peer-to-peer relationships) as well as from vertical collaboration (i.e. intergenerational peer-to-peer relationships). Either of them can be equally important in our educational biography.

\section{Conclusions}

A sustainable development for all mankind, future generations in particular, can only be reached if we stay within the planetary boundaries. In global policy-making, education is intended to be a key factor to align societies with this goal. However, while Education for Sustainable Development(ESD) has become a globally acclaimed approach to do so, critical pedagogical reflection is in order. This article argues that ESD must not be regarded as an educational strategy developed by policy-makers. Education does not want to be functionalized, its actors and institutions should not be seen as a lever for institutional change within the ESD framework. Instead, education chooses to approach these issues and participates in the debates because the engagement between a human being with the world is at its core already. It is the integral element of education's self-conception.

Education needs a pedagogical-didactic foundation from which guidelines for educators can be deduced. This article suggests that the idea of a general education as presented by the educationist Wolfgang Klafki can overcome this theoretical problem. When defining any educational content, the connection between the learner and the world (in any way thinkable) is at the core, laying specific stress to key issues that matter to every human being at any given time. People will acquire the skills and capabilities to grasp these collectively shared key issues within their historically constituted present while facing an emerging future and learn how to deal with the collective tasks of their time with a spirit of solidarity (cf. Klafki 1990, 94). Consequently, educationists act within the ESD framework not because it is urgent, but because it is a holistic way to enter the world.

ESD is the key concept intertwining ecological, social, economic, political, and cultural issues on a global scale for learners of all ages. Thus, it becomes evident that ESD is not a sequence of single topics which each have to be integrated in our curricula. ESD is not likely to be implemented in a linear way. On the contrary, ESD will gather its knowledge and experience from all kinds of disciplines and areas of life. Due to its transdisciplinary, holistic character ESD must not be mistaken for a sheer add-on to existing curricula. ESD has the potential to transform today's 
curricula fundamentally. This requires collaborative spaces of dialogue and transfer of knowledge between educators and students of all academic disciplines, educational institutions, local stakeholders, and CSO - spaces which specifically include perspectives from the Global South.

This article shows how such collaboration on various levels can be initiated in teacher education settings in $\mathrm{HEl}$ and how it can contribute to the transdisciplinary demands of ESD. Four fields of transdisciplinary collaboration in teacher education could be identified: content-related, institutional, and biography-affecting collaboration, as well as collaboration in pedagogical-didactic contexts. It will certainly be a challenge to tend to all of them at the same time, yet due to their manifold benefits all of them should be taken into consideration from the beginning. Integrating ESD into our current teacher education systems will remain a mammoth task and - if successful - will ultimately transform their systems. And while staying within the planetary boundaries will become the major collaborative challenge for mankind in the $21^{\text {st }}$ century, putting ESD into effect will be the major task for educators.

\section{Bibliography}

Fariol, F., Mayer M., \& del GobBo, G. (2017). "Learning for an unpredictable future: what competences for educators". Enseñanza de las Ciencias, N. ${ }^{\circ}$ Extraordinario, 4961-4966.

Gerten, D., \& Schellnhuber, H. J. (2016). "Planetare Grenzen, globale Entwicklung". In. U. SimOnis, H. LeitSCHUH, G. Michelsen et Al. (Eds.), Gesucht: Weltumweltpolitik. Herausforderungen im Anthropozän - Jahrbuch Ökologie 2016 (pp. 11-19). Stuttgart: Hirzel.

Hoßß, Ch. (2019). Deutschunterricht im Anthropozän. Didaktische Konzepte einer Bildung für nachhaltige Entwicklung. Munich: Electronic University Publications. (https://edoc.ub.uni-muenchen.de/24608/1/Hoiss_Christian.pdf, accessed on 11 April 2020)

KlafKl, W. (1990). "Abschied von der Aufklärung? Grundzüge eines bildungstheoretischen Gegenentwurfs". In H.-H. KRÜGER (Ed.): Abschied von der Aufklärung? Perspektiven der Erziehungswissenschaft (pp. 91-104). Opladen: Leske + Budrich. 
KLAFKI, W. (2007). Neue Studien zur Bildungstheorie und Didaktik. Zeitgemäße Allgemeinbildung und kritisch-konstruktive Didaktik. 6th ed. Weinheim: Beltz.

KRUSE, L. (2005). "Nachhaltigkeitskommunikation und mehr: die Perspektive der Psychologie". In G. Michelsen, \& J. Godemann (Eds.), Handbuch Nachhaltigkeitskommunikation (pp. 109-120). München: oekom.

Michelsen, G., \& FisCher, D. (2016). "Bildung für nachhaltige Entwicklung". In K. OT, J. Dierks \& L. Voget-KLeSCHIN (Eds.), Handbuch Umweltethik (pp. 330-334). Stuttgart: Metzler.

Rockström, J.; Steffen, W.; NoOne, K. et al. (2009). "A safe operating space for humanity". Nature, 461, 472-475.

RSP - A Rounder Sense of Purpose (2018). Project Website (www. aroundersenseofpurpose.ev; accessed on 11 April 2020).

Scom, W., \& VARE, P. (2017). "The World We'll Leave Behind. Grasping the Sustainability Challenge". London, New York: Routledge.

Steffen, W.; Broadgate, W.; Deutsch, L. et al. (2015). "The trajectory of the Anthropocene. The Great Acceleration". The Anthropocene Review, 2 (1), 81-98.

StOLtenBeRG, U.; \& Holz, V. (Eds.) (2017). LENA - LehrerInnenbildung für eine nachhaltige Entwicklung. Stand und Entwicklungsperspektiven. Lüneburg: Leuphana Universität.

UN - United Nations (2015). Sustainable Development Goals. Project Website (https://sustainabledevelopment.un.org/?menu=1300; accessed on 11 April 2020).

UNECE - United Nations EConomic Commission for EuRope (2011). Learning for the Future. Competences in Education for Sustainable Development. Geneva: UNECE (https://www.unece.org/fileadmin/DAM/env/esd/ESD_Publications/ Competences_Publication.pdf; accessed on 11 April 2020).

UNeP - United Nations Environment Programme (2013). The Emissions Gap Report. A UNEP Synthesis Report. Nairobi: United Nations Environment Programme.

UNESCO - United Nations Educational, Scientific and Cultural Organization (2019). Educational content up close: examining the learning dimensions of Education for Sustainable Developmentand Global Citizenship Education. Paris: UNESCO(https:// unesdoc.unesco.org/ark:/48223/pf0000372327; accessed on 11 April 2020). 